\title{
Analisa Ketelitian Planimetris Citra Quickbird Guna Menunjang Kegiatan Administrasi Pertanahan (Studi Kasus: Kabupaten Gresik, 7 Desa Prona)
}

\author{
Theo Prastomo Soedarmodjo ${ }^{1)}$, Agung Budi Cahyono ${ }^{1)}$, Dwi Budi Martono ${ }^{2)}$ \\ ${ }^{1)}$ Program Studi Teknik Geomatika, Fakultas Teknik Sipil dan Perencanaan, Institut Teknologi \\ Sepuluh Nopember (ITS) ${ }^{2)}$ Kantor Pertanahan Kabupaten Gresik \\ Email: agungbc@geodesy.its.ac.id ${ }^{1)}$,dwibudimartono@gmail.com ${ }^{2)}$
}

\begin{abstract}
Abstrak - Pembuatan peta dasar dalam menunjang kegiatan administrasi pertanahan yang selama ini menggunakan cara terrestrial dan fotogrametri belum mampu memenuhi dan mencakup seluruh wilayah Indonesia. Saat ini Kabupaten Gresik sedang mengadakan program kadaster lengkap. Dibutuhkan peta dasar dalam memenuhi program tersebut, dimana peta dasar diperoleh secara cepat dan akurat menggunakan data berupa citra satelit resolusi tinggi. Pada penelitian ini diteliti hasil dari kemungkinan data citra satelit resolusi tinggi yang dimiliki oleh Kantor Pertanahan Kabupaten Gresik dapat memenuhi ketentuan dalam peraturan yang telah ditetapkan. Digunakan data berupa citra satelit resolusi tinggi (Quickbird 2007), 9 buah titik kontrol, 13 titik uji dan 17 percobaan jarak yang dilakukan pengukuran dilapangan. Data dasar berupa citra satelit tersebut dilakukan proses pan-sharpening dan pemotongan sesuai lokasi studi kasus. Kemudian dilakukan koreksi geometrik menggunakan 9 buah titik kontrol. Serta dilakukan proses uji akurasi horizontal CE90 menggunakan 13 buah titik kontrol. Dilakukan pula proses Pengukuran jarak di lapangan sebanyak 17 percobaan kemudian dibandingkan dengan intrepretasi objek di citra. Terdapat pula proses uji statistik dari masing-masing pengukuran jarak. Kemudian setelah proses uji statistik dilakukan proses uji planimetris jarak di lapangan. Dari hasil penelitian didapat nilai hasil besaran koreksi geometrik menggunakan metode polynomial orde-1 (Metode Affine) sebesar 0,515. Dilakukan pula proses uji statistik metode t-test dimana terdapat satu data yang ditolak. Dari hasil data yang diterima didapatkan nilai RMSe dari pengukuran jarak dilapangan yang menunjukkan besar ketelitian planimetris yaitu sebesar 0,245 meter. Terakhir, diperoleh hasil perhitungan ketelitian geometrik untuk penentuan nilai akurasi horizontal sebesar 0.711 meter. Nilai tersebut penggunaan skala 1:2500 untuk di daerah pertanian dan skala 1:10000 untuk daerah perkebunan besar.
\end{abstract}

Kata Kunci-Administrasi Pertanahan, Citra Satelit Resolusi Tinggi, Ketelitian Planimetris

\section{PENDAHULUAN}

$\mathrm{P}$ ENGGUNAAN penginderaan jauh dapat mencakup suatu areal yang luas dalam waktu bersamaan. Penginderaan jauh dapat digunakan untuk penelitian lingkungan hidup mengenai interaksi antara sistem alam dan bumi. [1] Penginderaan jauh dapat digunakan untuk menganalisis spasial secara cepat, efektif, efisien dan dapat mencakup wilayah yang lebih luas bila dibandingkan dengan pengukuran langsung yang membutuhkan biaya serta tenaga yang lebih banyak. Perkembangan teknologi penginderaan jauh terutama citra satelit resolusi tinggi memudahkan dalam mengindetifikasi persil dari sebuah daerah. Citra resolusi tinggi yang kini banyak mendapat respon positif dari para pemegang keperluan, contohnya pada bidang administrasi pertanahan di pemerintahan. Didorong pula dengan ketersediaan data yang selalu ada di lapangan yang mengakibatkan pemerintah mulai melirik teknologi ini.

Administrasi pertanahan merupakan suatu usaha dan kegiatan suatu organisasi dan manajemen yang berkaitan dengan penyelenggaraan kebijakan-kebijakan pemerintah di bidang pertanahan dengan menggerakan sumberdaya untuk mencapai tujuan sesuai perundang-undangan yang berlaku [2]. Pembuatan peta dasar dalam menujang kegiatan administrasi pertanahan yang selama ini menggunakan cara terrestrial dan fotogrametri belum mampu memenuhi dan mencakup seluruh wilayah Indonesia. Masih banyak bidang-bidang tanah yang belum terdaftar dan titik-titik dasar teknik yang belum terpasang, yang seharusnya menjadi titik ikat bagi pengukuran detail terhadap bidang-bidang tanah tersebut agar tidak melayang.

Kabupaten Gresik merupakan wilayah penyangga Kota Surabaya yang memiliki tingkat pertumbuhan ekonomi yang cukup tinggi, melebihi tingkat pertumbuhan provinsi Jawa Timur maupun nasional dalam lima tahun terakhir. Tingkat pertumbuhan ini membutuhkan tanah yang harus ditata dengan benar. Diperlukan administrasi pertanahan yang lengkap, baik dan benar. Dengan menggunakan citra satelit resolusi tinggi informasi geospasial untuk keperluan administrasi pertanahan yang lengkap akan lebih cepat dibangun dari pada bila harus dibuat dengan metode terestris. Saat ini kabupaten Gresik sedang mengadakan program pembangunan Kadaster Lengkap atau bisa disebut dengan KAKAP. KAKAP itu sendiri merupakan informasi tekstual atau atribut dari kadaster, seperti nilai tanah, kepemilikan atau penggunaan, yang dapat diakses oleh kode-kode paket yang unik dimana dapat ditampilkan pada peta kadaster. Dalam pemenuhan program tersebut dibutuhkan peta dasar, dimana dalam mendapatkan data peta dasar secara cepat dan akurat metode yang ditempuh menggunakan data berupa citra satelit resolusi tinggi. Pembangunan KAKAP difasilitasi oleh Kementerian Agraria dan Tata Ruang melalui aplikasi komputerisasi kantor pertanahan berbasis web. Jika kakap berhasil disukseskan, maka integrasi BPN dan Tata Ruang pada Kementerian Agraria dan Tata Ruang akan 
mewujudkan tanah untuk ruang hidup yang memakmurkan dan menentramkan.

Dalam penyediaan peta data dasar diperlukan adanya proses transformasi koordinat citra kedalam koordinat real dengan metode yang tepat sehingga didapatkan citra yang memiliki ketelitian yang tinggi. Penelitian ini dilakukan dengan menganalisa tingkat kesalahan RMSe dari titik sebaran GCP (Ground Control Point), ICP (Independent Check Point) dan tingkat kekuatan jaring (SoF) serta ketelitian planimetris yang nantinya dapat digunakan untuk memenuhi kegiatan administrasi pertanahan di kabupaten Gresik berupa Kadaster Lengkap.

\section{A. Batasan Masalah}

Batasan masalah dalam penelitian ini meliputi:

1) Wilayah penelitian meliputi 7 desa lokasi Prona tahun 2015 Kantor Pertanahan Kabupaten Gresik.

2) Data dasar berupa citra Quickbird (tahun 2007) yang diperoleh dari Kantor Pertanahan Kabupaten Gresik.

3) Menggunakan data 9 titik GCP (Ground Control Point) dan 13 titik ICP (Independent Check Point)

4) Hasil Penelitian ini berupa analisis ketelitian planimetris citra satelit resolusi tinggi sesuai standar ketentuan Badan Pertanahan Nasional.

\section{B. Tujuan Penelitian}

Tujuan dilakukannya penelitian ini adalah:

1) Mengevaluasi hasil koreksi geometrik citra satelit resolusi tinggi sebagai peta dasar guna menunjang kegiatan administrasi pertanahan.

2) Menganalisis hasil ketelitian planimetris citra satelit resolusi tinggi menurut Peraturan Pemerintah No. 24 Tahun 1997 dalam Pasal 17 Tentang Pendaftaran Tanah.

\section{METODOLOGI PENELITIAN}

Lokasi yang digunakan untuk penelitian Tugas Akhir ini adalah mencakup studi kasus 7 desa di Kabupaten Gresik. Secara geografis wilayah Kabupaten Gresik terletak antara $112^{\circ}$ - $113^{\circ}$ BT dan $7^{\circ}-8^{\circ}$ LS. Adapun 7 desa yang dimaksud mencakup:

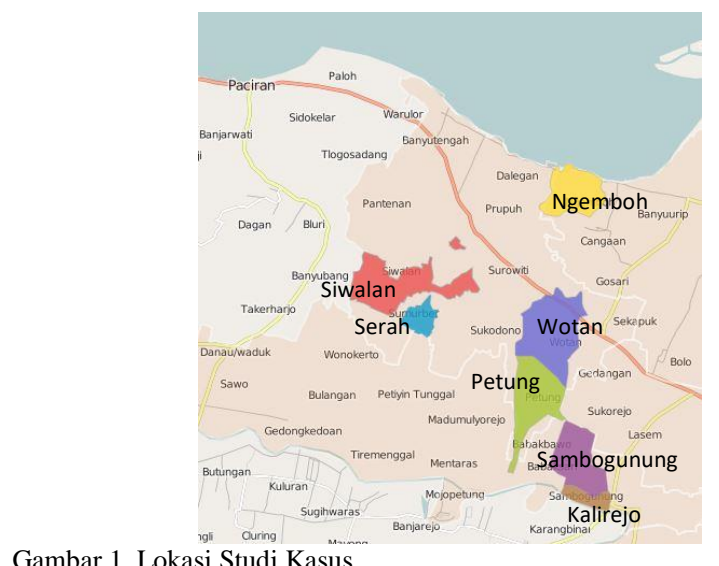

Gambar 1. Lokasi Studi Kasus

\section{A. Alat dan Bahan}

1) Alat

Peralatan yang digunakan dalam penelitian Tugas Akhir ini Laptop, Printer, Roll Meter, Microsoft Office 2013, Microsoft Excel 2013, ArcGIS, Perangkat Lunak Komputasi, Perangkat Lunak Pengolah Citra

\section{2) Bahan}

Bahan yang digunakan dalam penelitian Tugas Akhir ini adalah Citra satelit resolusi tinggi wilayah Kabupaten Gresik yakni Citra Quickbird, Data titik kontrol horizontal berupa 9 titik GCP (Ground Control Point) dan 13 titik ICP (Independent Check Point) yang didapat dari Kantor Pertanahan Kabupaten Gresik.

\section{B. Metodologi Penelitian}

Berikut diagram pengolahan pengerjaan Penelitian

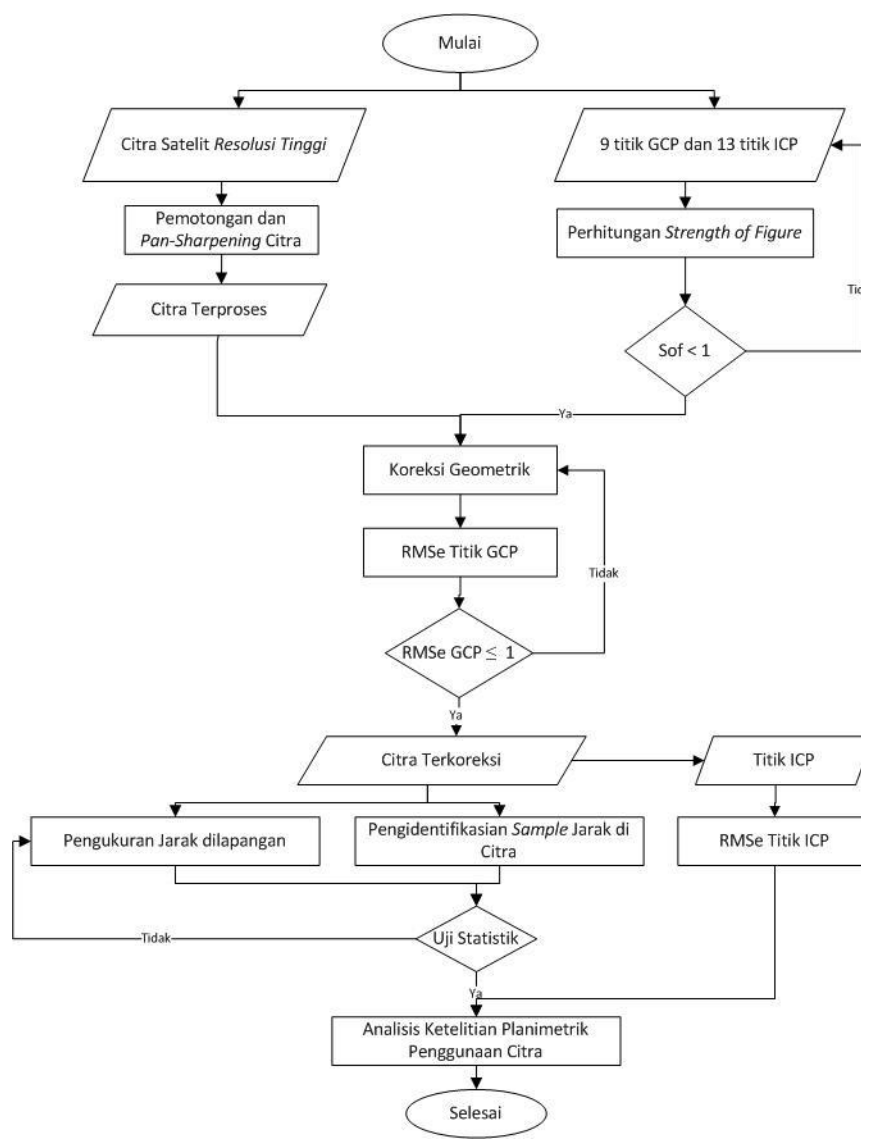

Gambar 2. Diagram Air Pengolahan

\section{HASIL}

\section{A. Hasil Pemotongan dan Pan-sharpen Citra}

Dalam Penelitian ini didapatkan Citra Satelit Resolusi Tingi dari Badan Pertanahan Nasional (BPN) berupa citra Quickbird tahun 2007. Sebelum melakukan pengolahan citra lebih lanjut dilakukan proses pan-sharpen citra agar memiliki resolusi spasial yang tinggi. Pan-sharpen ini dilakukan menggunakan perangkat lunak pengolah citra dengan menggabungkan citra pankromatik dengan resolusi spasial 0.6 meter dengan citra multispektral dengan resolusi spasial 2.4 meter proses ini 
dinamakan dengan proses pan-sharpen, sehingga didapatkan kenampakan citra dengan resolusi spasial sebesar 0.6 meter.

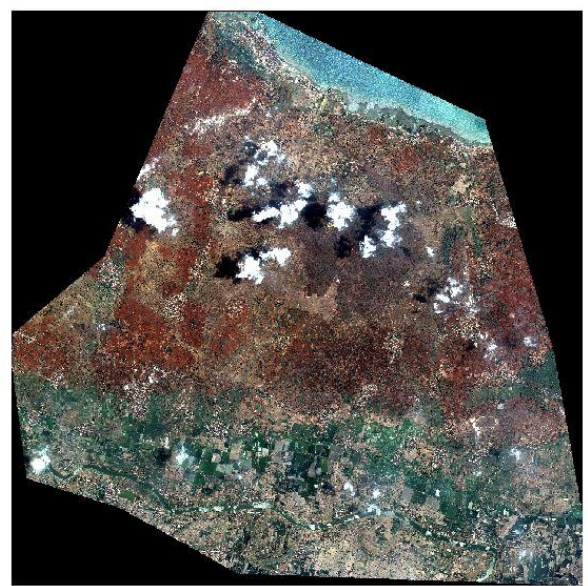

Gambar 3. Citra Satelit Quickbird terpotong dan terproses pan-sharpen

Kemudian dilakukan proses pemotongan sesuai cakupan studi kasus yang dipilih. Dalam melakukan pemotongan citra juga memperhatikan persebaran titik kontrol agar sesuai dengan syarat persebaran titik kontrol. Luasan dari lokasi penelitian agar mencakup studi kasus sebesar 192,885 km².

\section{B. Hasil Persebaran Titik}

Titik yang digunakan sebagai titik kontrol tanah (GCP) dan titik uji (ICP) diperhatikan persebarannya.

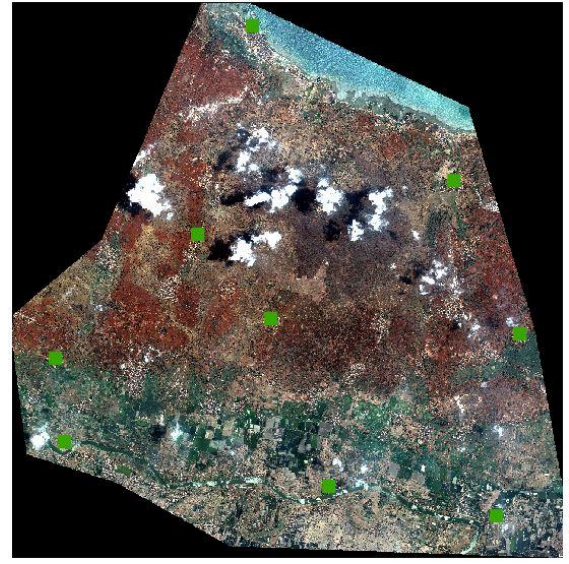

Gambar 4. Persebaran titik kontrol tanah (GCP)

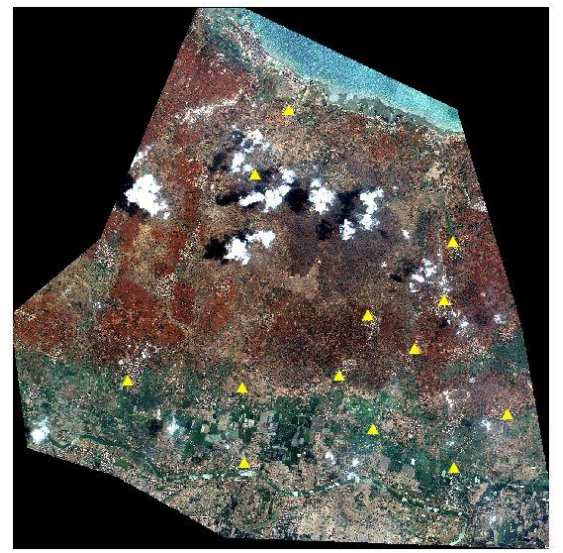

Gambar 5. Persebaran titik uji (ICP)

Sebaran titik kontrol tanah (GCP) dengan memperhatikan:
- Pada sisi perimeter area citra;

- Pada Tengah area/scene;

- Tersebar secara merata dalam area citra;

Kemudian untuk persebaran titik uji (ICP) dengan memperhatikan:

- Objek yang digunakan sebagai titik uji harus memiliki sebaran yang merata diseluruh area yang akan diuji

- Pada setiap kuadran jumlah minimum titik uji adalah $20 \%$ dari total titik uji.

- Jarak antar titik uji minimum 10\% dari jarak diagonal area yang diuji

- Untuk area yang tidak beraturan, pembagian kuadran dilakukan dengan membagi wilayah kelompok data menjadi empat bagian, dimana setiap bagian dipisahkan oleh sumbu silang. Pembagian kuadran dibuat sedemikian rupa sehingga jumlah dan sebaran titik uji mempresentasikan wilayah yang akan diuji.

\section{Hasil Perhitungan Nilai Strength of Figure (SoF)}

Berikut hasil perhitungan strength of figure (SoF)

Jumlah Titik $\quad: 9$ Titik

Jumlah Baseline : 17 Baseline

N Ukuran $\quad:$ Baseline $\times 2=17 \times 2=34$

N Parameter $\quad:$ Titik $\times 2=7 \times 2=14$

$\mathrm{U}=\mathrm{N}$ Ukuran $-\mathrm{N}$ Parameter $=34-14=20$

SoF $=\frac{\left\{(\text { trace }) A^{T} \cdot A\right\}^{-1}}{U}$

SoF $=0.381$

Perhitungan strength of figure mendapatkan Nilai 0,381 yang berarti desain jaring memenuhi nilai toleransi yang diberikan sebesar 1 sehingga desain jaring dianggap kuat.

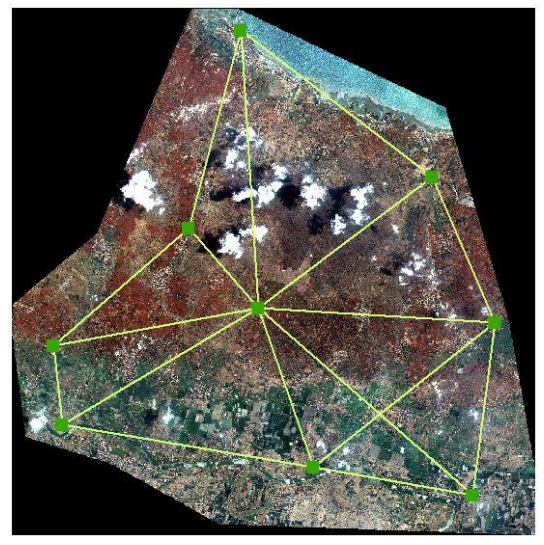

Gambar 6. Desain jaring strength of figure

\section{Hasil Koreksi Geometrik}

Koreksi geometrik dilakukan untuk peningkatan mutu citra dengan tujuan mendapatkan ketelitian yang tinggi. Koreksi geometrik Citra Quickbird dilakukan dengan menggunakan data titik kontrol tanah (GCP) yang didapat dari BPN. Jumlah titik kontrol tanah (GCP) yang digunakan sebanyak 9 titik yang tersebar di seluruh daerah penelitian. 
Pemberian koordinat pada citra menggunakan perangkat lunak pengolah citra dimana dalam perangkat tersebut menggunakan metode koreksi geometrik polynomial orde-1 (metode Affine). Dalam proses koreksi geometrik megunakan perangkat lunak pengolah citra menggunakan menu Registration Image to map.

RMS error yang dihasilkan dari 9 titik kontrol tanah (GCP) yang tersebar merata di lokasi Penelitian sebesar 0.515 yang telah memenuhi toleransi yang diberikan yaitu sebesar $<1$ pixel . Nilai dari RMS error menunjukkan nilai kesalahan yang terjadi dalam proses koreksi geometrik.

\section{E. Hasil Interpretasi Posisi Titik Uji}

Proses interpretasi titik uji dimaksudkan untuk mengetahui besar kesalahan dari hasil koreksi geometrik yang nantinya akan disesuaikan dengan ketentuan yang telah diberikan oleh Badan Informasi Geospasial (BIG) dan Badan Pertanahan Nasional (BPN). Dalam proses interpretasi titik uji ini menggunakan perangkat lunak berupa ArcGIS dengan jumlah titik uji sebanyak 13 titik sesuai ketentuan yang diberikan badan Informasi geospasial untuk cakupan wilayah penelitian $<250$ km2 yaitu minimum 12 titik. Berikut hasil interpretasi titik uji.

\begin{tabular}{|c|c|c|c|c|c|}
\hline \multirow{2}{*}{ No } & \multirow{2}{*}{$\begin{array}{l}\text { Titik } \\
\text { ICP }\end{array}$} & \multicolumn{2}{|c|}{ Koordinat ICP (GPS) } & \multicolumn{2}{|c|}{ Koordinat ICP (Interpretasi) } \\
\hline & & X_GPS & Y_GPS & X_Citra & Y_Citra \\
\hline 1 & CP1 & 195894.940 & 737064.320 & 195894.934 & 737063.927 \\
\hline 2 & $\mathrm{CP} 2$ & 194870.460 & 735102.500 & 194870.728 & 735102.023 \\
\hline 3 & CP3 & 200960.470 & 733023.640 & 200960.166 & 733023.307 \\
\hline 4 & $\mathrm{CP} 4$ & 200661.560 & 731224.310 & 200661.698 & 731224.737 \\
\hline 5 & CP5 & 198319.390 & 730756.220 & 198319.827 & 730756.374 \\
\hline 6 & CP6 & 190931.440 & 728758.990 & 190931.692 & 728758.487 \\
\hline 7 & $\mathrm{CP} 7$ & 194461.970 & 728534.900 & 194462.299 & 728534.568 \\
\hline 8 & CP8 & 197450.990 & 728913.850 & 197451.364 & 728913.445 \\
\hline 9 & СР9 & 199771.130 & 729725.530 & 199771.320 & 729725.273 \\
\hline 10 & $\mathrm{CP} 10$ & 194517.270 & 726241.960 & 194517.220 & 726241.417 \\
\hline 11 & $\mathrm{CP} 11$ & 198469.670 & 727271.260 & 198469.509 & 727271.458 \\
\hline 12 & $\mathrm{CP} 12$ & 200979.570 & 726092.800 & 200979.068 & 726093.076 \\
\hline 13 & $\mathrm{CP} 13$ & 202618.970 & 727723.670 & 202618.595 & 727723.774 \\
\hline
\end{tabular}

\section{F. Hasil Pengukuran Jarak Lapangan}

Pengukuran jarak dilapangan digunakan untuk membandingkan jarak hasil interpretasi citra dengan jarak hasil pengukuran langsung dilapangan. Dalam penelitian ini menggunakan 17 objek pengukuran jarak dimana objek pengukuran jarak tersebut tersebar kedalam masing-masing desa dalam studi kasus penelitian ini. Pada pengukuran ini digunakan 3 kali proses interpretasi jarak pada citra satelit.

\section{PEMBAHASAN}

\section{A. Analisa Ketelitian Geometrik}

Dari hasil koreksi geometrik kemudian dilakukan proses uji ketelitian geometrik mengunakan titik uji (ICP) yang tersebar merata sesuai ketentuan yang telah diberikan Badan Informasi Geospasial (BIG). Kemudian dilakukan perhitungan nilai akurasi horizontal dari citra hasil koreksi geometrik. Dalam penelitian ini menggunakan 13 titik uji (ICP).
Dari hasil perhitungan ini nantiya didapat nilai root mean squere error (RMSe) dari jumlah titik uji yang ada. Kemudian akan didapatkan pula besaran nilai dari akurasi horizontal citra satelit resolusi tinggi yang telah dilakukan proses koreksi geometrik. Berikut hasil perhitungan ketelitian horizontal citra satelit.

Tabel 2. Nilai akurasi titik uji (ICP)

\begin{tabular}{ccc}
\hline \hline Titik ICP & $\begin{array}{c}\text { Jarak antara ICP (GPS) } \\
\text { dengan ICP (Interpretasi) }\end{array}$ & $\left(\mathrm{X}_{\mathrm{GPS}}-\mathrm{X}_{\mathrm{CP}}\right)^{2}+\left(\mathrm{Y}_{\mathrm{GPS}}-\mathrm{Y}_{\mathrm{CP}}\right)^{2}$ \\
\hline $\mathrm{CP} 1$ & 0.393 & 0.155 \\
$\mathrm{CP} 2$ & 0.547 & 0.299 \\
$\mathrm{CP} 3$ & 0.451 & 0.204 \\
$\mathrm{CP} 4$ & 0.449 & 0.202 \\
$\mathrm{CP} 5$ & 0.463 & 0.214 \\
$\mathrm{CP} 6$ & 0.562 & 0.316 \\
$\mathrm{CP} 7$ & 0.467 & 0.218 \\
$\mathrm{CP} 8$ & 0.552 & 0.305 \\
$\mathrm{CP} 9$ & 0.320 & 0.102 \\
$\mathrm{CP} 10$ & 0.545 & 0.297 \\
$\mathrm{CP} 11$ & 0.255 & 0.065 \\
$\mathrm{CP} 12$ & 0.573 & 0.328 \\
$\mathrm{CP} 13$ & 0.389 & 0.151 \\
& Jumlah (13CP) & 2.856 \\
\multicolumn{2}{c}{ Rata-rata (13CP) } & 0.459 \\
Akurasi Horisontal (13CP) & 0.469 \\
\hline \hline
\end{tabular}

Keterangan:

$\operatorname{RMSEr}(13 \mathrm{CP})=\sqrt{\sum(\mathrm{XGPS}-\mathrm{XCP})_{2}+(\mathrm{YGPS}-\mathrm{YCP})_{2} / \sum \text { Titik }}$

Akurasi Horisontal $(13 \mathrm{CP})=1,5175 \times \mathrm{RMSEr}$

Nilai Akurasi horizontal didapat dengan menggunakan CE90 yang dihitung dari nilai RMSe resolusi citra setelah terkoreksi geometrik. Nilai akurasi horizontal dengan tingkat kepercayaan pada level 90\%. [3]

Hasil nilai perhitungan ICP tersebut diatas menghasilkan nilai RMSe pada 13 titik uji dimana sebesar 0.469 meter. Nilai ini menunjukkan besar kesalahan rata-rata dari seluruh hasil intrepretasi dari titik uji. Kemudian didapat pula besar nilai akurasi horizontal yaitu sebesar 0.711 meter dimana menunjukkan besar kesalahan atau perbedaan posisi horizontal objek di peta dengan posisi yang dianggap sebenarnya tidak lebih besar dari radius tersebut.

\section{B. Analisa Uji Statistik t-test Pengukuran Jarak}

Berikut hasil analisa uji statistik t-test dari hasil pengukuran jarak di lapangan dengan pengukuran jarak interpretasi. Dilakukan proses pengukuran jarak di lapangan sebanyak 17 kali percobaan yang tersebar merata dimasingmasing desa studi kasus.

Pada proses uji statistik Metode student $t$ t-test dimana menggunakan derajat kepercayaan sebesar $95 \%$. Sehingga level of significance $\alpha=5 \%$ serta derajat kebebasan 2 ( $\mathrm{n}=$ jumlah pengukuran - 1), maka diperoleh nilai :

$t_{n}, 1 / 2 \alpha=\mathrm{t}_{2} ; 0,025=4,303$ (dari tabel studest $t$-test)

Dengan metode uji statistik t-test akan didapat nilai yang akan diterima apabila ukuran dalam batas $\mathrm{x}_{1}<\mathrm{X}<\mathrm{x}_{2}$. 
Tabel 3 Tabel hasil uji statistik $t$-test dengan $\alpha=5 \%$

\begin{tabular}{cccccc}
\hline \hline Nama & $\begin{array}{c}\text { Jarak } \\
\text { Rata-rata } \\
\text { Cbjek }(\mathrm{m})\end{array}$ & $\begin{array}{c}\text { Jarak } \\
\text { Langan } \\
(\mathrm{m})\end{array}$ & $\mathrm{x}_{1}$ & $\mathrm{x}_{2}$ & Keterangan \\
\hline D02 & 29.459 & 29.540 & 28.102 & 30.978 & Ho Diterima \\
D03 & 57.075 & 56.850 & 56.303 & 57.397 & Ho Diterima \\
D04 & 50.608 & 50.330 & 49.492 & 51.168 & Ho Diterima \\
D05 & 67.549 & 67.310 & 66.983 & 68.637 & Ho Diterima \\
D06 & 27.799 & 27.510 & 26.369 & 28.651 & Ho Diterima \\
D07 & 68.557 & 68.350 & 67.317 & 69.383 & Ho Diterima \\
D09 & 69.325 & 69.030 & 68.192 & 69.868 & Ho Diterima \\
D10 & 68.596 & 68.360 & 67.630 & 69.090 & Ho Diterima \\
D12 & 29.278 & 29.650 & 29.035 & 30.265 & Ho Diterima \\
D13 & 11.632 & 11.340 & 10.646 & 12.034 & Ho Diterima \\
D14 & 22.290 & 22.380 & 21.513 & 23.247 & Ho Diterima \\
D16 & 24.447 & 24.500 & 24.034 & 24.966 & Ho Diterima \\
D17 & 21.757 & 22.010 & 21.205 & 22.815 & Ho Diterima \\
D18 & 31.987 & 31.710 & 30.726 & 32.694 & Ho Diterima \\
D20 & 7.959 & 9.380 & 8.122 & 10.638 & Ho Ditolak \\
D22 & 45.472 & 45.180 & 43.475 & 46.885 & Ho Diterima \\
D23 & 43.719 & 43.520 & 42.533 & 44.507 & Ho Diterima \\
\hline \hline
\end{tabular}

Proses uji statistik metode t-test menghasilkan nilai yang diterima dari 17 percobaan pengukuran jarak namun terdapat 1 percobaan jarak yang ditolak sehingga untuk mengurangi besar kesalahan planimetris maka data tersebut dianggap blunder dan tidak dipakai untuk proses selanjutnya.

\section{Analisa Pengukuran Jarak}

Hasil pengukuran jarak dilapangan dibandingkan dengan hasil interpretasi jarak di citra kemudian didapatkan nilai RMSe dari hasil pengukuran jarak yang dilakukan.

Nilai RMSe pengukuran yaitu sebesar 0,245 meter. Hal ini menunjukkan besar nilai keteletian planimetris citra yang digunakan.

\section{Analisa Planimetris Penggunaan Citra}

Dari hasil perhitungan titik kontrol tanah dan titik uji ditemukan nilai RMSe dari titik kontrol tanah sebesar 0.515 dimana nilai ini telah standart yang ada yaitu sebesar $<1$ pixel.

Menurut Peraturan Menteri Negara Agraria/Kepala Badan Pertanahan Nasional No. 3 Tahun 1997 tentang Ketentuan Pelaksanaan Peraturan Pemerintah No. 24 Tahun 1997 tentang Pendaftaran Tanah dalam Pasal 17, Peta Dasar Pendaftaran tanah dapat dibuat dengan memenuhi syarat peta tersebut mempunyai skala 1:1000 atau lebih besar untuk daerah perkotaan, 1:2500 atau lebih besar untuk daerah pertanian dan 1:10000 atau lebih besar untuk daerah perkebunan besar [4] dan mempunyai ketelitian planimetris lebih besar atau sama dengan $0,3 \mathrm{~mm}$ pada skala peta. Dimana dalam Perka BIG Nomor 15 Tahun 2014 tentang pedoman teknis ketelitian peta dasar masuk dalam kelas 2.

Pada pergukuran jarak yang dilakukan, didapatakan nilai ketelitian planimetris dari hasil perhitungan rata-rata RMSe dari masing-masing pengukuran jarak dilapangan yaitu sebesar 0,245 meter. Nilai ketelitian planimetris ini memenuhi dalam skala 1:1000 dimana besar toleransi yang diberikan yaitu lebih besar atau sama dengan $0,3 \mathrm{~mm}$ pada skala peta.

Kemudian dalam perhitungan ketelitian geometrik dengan menggunakan 13 titik uji (ICP) hasil perhitungan tersebut menunjukkan nilai ketelitian memenuhi seperti dibawah ini.

\begin{tabular}{ccccc}
\multicolumn{5}{c}{ Tabel 4. Nilai Standart kelas 2 } \\
\hline \hline \multirow{2}{*}{ Ketelitian } & $\begin{array}{c}\text { Hasil } \\
\text { Uji } \\
\end{array}$ & Standart Kelas 2 \\
& CE90 & $1: 1000$ & $1: 2500$ & $1: 10000$ \\
\hline Horizontal & 0.711 & $0.3 \mathrm{~m}$ & $0.75 \mathrm{~m}$ & $3 \mathrm{~m}$ \\
\hline \hline
\end{tabular}

Keterangan

Nilai standart ketelitian yang terpenuhi

Dari tabel diatas terlihat bahwa nilai hasil perhitungan ketelitian geometrik dari citra satelit resolusi tinggi (Quckbird tahun 2007) yang didapat dari Kantor Pertanahan Kabupaten Gresik memenuhi standart ketelitian peta dasar dengan skala 1 : 2500 dan skala $1: 10000$. Sehingga guna menunjang kegiatan admnistrasi pertanahan menurut hasil dari penilitian ini hanya mampu memenuhi untuk proses penggunaan standart ketelitian yaitu dengan 1:2500 atau lebih besar untuk daerah pertanian dan 1:10000 atau lebih besar untuk daerah perkebunan besar.

\section{KESIMPULAN}

Berdasarkan penelitian ini, dapat disimpulkan beberapa hal yaitu:

1) Dari hasil proses koreksi geometrik citra satelit resolusi tinggi (Quickbird 2007) dengan 9 buah titik kontrol tanah (GCP) didapatkan nilai hasil besaran ketelitian geometrik menggunakan metode polynomial orde-1 (Metode Affine) sebesar 0,515 dimana nilai tersebut kurang dari 1 pixel.

2) Hasil perhitungan jarak objek dilapangan dan jarak objek interpretasi mendapatkan nilai rata-rata RMSe dari masingmasing pengukuran jarak dilapangan yaitu sebesar 0,245 meter. Nilai ketelitian planimetris ini memenuhi dalam skala 1:1000 dimana besar toleransi yang diberikan yaitu lebih besar atau sama dengan $0,3 \mathrm{~mm}$ pada skala peta.

3) Dari hasil perhitungan ketelitian geometrik untuk menentuan besar akurasi horizontal penggunaan data citra sebagai peta dasar menggunakan 13 titik uji (ICP) yang tersebar merata didapat nilai akaurasi horizontal sebesar 0.711 meter. Nilai tersebut menurut peraturan Perka BIG Nomor 15 Tahun 2014 tentang pedoman teknis ketelitian peta dasar masuk memenuhi standart ketelitian peta dasar dengan skala $1: 2500$ dan skala $1: 10000$. Namun tidak memenuhi skala $1: 1000$. Kemudian dalam menunjang kegiatan admnistrasi pertanahan menurut hasil dari penilitian ini hanya mampu memenuhi untuk proses penggunaan standart ketelitian 1:2500 atau lebih besar untuk daerah pertanian dan 1:10000 atau lebih besar untuk daerah perkebunan besar. 


\section{UCAPAN TERIMA KASIH}

Penulis mengucapkan terima kasih kepada Kantor Pertanahan Kabupaten Gresik yang telah memberikan dukungan dalam penyediaan data Tugas Akhir dan Direktorat Jenderal Pendidikan Tinggi (Ditjen Dikti) Kementerian Pendidikan dan Kebudayaan yang telah melalui program Bidikmisi memberikan bantuan biaya Pendidikan selama tahun 2012-2016.

\section{DAFTAR PUSTAKA}

[1] A. Puntodewo, Sistem Informasi Geografis Unutk Pengelolaan Sumberdaya Alam, Bogor: Center for International Forestry Research, 2003.

[2] R. Murad, Administrasi Pertanahan : Pelaksanaan Hukum dalam Praktek, Bandung: Mandar Maju, 1997.

[3] Kepala Badan Informasi Geospasial, Peraturan Kepala Badan Informasi Geospasial Nomor 15 Tahun 2014 Tentang Pedoman Teknis Ketelitian Peta Dasar, Jakarta, 2014

[4] M. N. A. B. P. Nasional, Peraturan Menteri Negara Agraria/Kepala Badan Pertanahan Nasional Nomor 3 Tahun 1997 Tentang Ketntuan Pelaksanaan Peraturan Pemerintah Nomor 24 Tahun 1997 Tentang Pendaftaran Tanah, 1997 pasal 17. 